\title{
Inferências pedológicas aplicadas ao perímetro irrigado de Custódia, $\mathrm{PE}^{(1)}$
}

\author{
Lindomário Barros de Oliveira(2), Mateus Rosas Ribeiro(2), Maria da Graça de Vasconcelos Xavier Ferreira(3), \\ José Fernando Wanderley Fernandes de Lima ${ }^{(2)}$ e Flávio Adriano Marques ${ }^{(2)}$
}

\begin{abstract}
Resumo - O objetivo deste trabalho foi avaliar as propriedades e o comportamento de solos aluviais do perímetro irrigado de Custódia, PE, cujo uso agrícola foi interrompido em virtude de problemas de salinidade/sodicidade. Foram realizadas caracterizações morfológica, física, química e mineralógica de três perfis de solos afetados por sais do referido perímetro irrigado. Os solos foram classificados, de acordo com o Sistema Brasileiro de Classificação de Solos, como Neossolo Flúvico Ta eutrófico solódico, Neossolo Flúvico Sódico salino e Neossolo Flúvico Sódico típico. A estratificação, típica de solos de natureza aluvial, rege o comportamento físico e químico dos solos estudados no sentido vertical. Apesar da presença de minerais que podem contribuir com o processo de salinização/sodificação, tal contribuição deve ser irrisória quando comparada à das águas de rega de baixa qualidade. A reutilização destes solos com agricultura irrigada deve ser precedida do uso de corretivos e da introdução de um eficiente sistema de drenagem que impeça a ascensão do lençol freático e promova a lixiviação do sódio.
\end{abstract}

Termos para indexação: solo sódico, salinidade, propriedade físico-química do solo, aspecto morfológico do solo, semi-árido.

\section{Pedological inferences applied to Custódia irrigated perimeter, in Pernambuco State, Brazil}

Abstract - This work was carried out to evaluate the properties and the behavior of alluvial soils of the Custódia irrigated perimeter, in Pernambuco State, Brazil, whose agricultural use was interrupted due to salinity/sodicity problems. Morphologic, physics, chemistry and mineralogical characterizations of three profiles of affected soils for salts of the referred irrigated perimeter was used. The soils were classified, in agreement with the Brazilian System of Classification of Soils, as Solodic Eutric Fluvic Neosol, Saline Sodic Fluvic Neosol and Typic Sodic Fluvic Neosol. The stratification, what is typical in alluvial soils, governs the physical and chemical behavior of the soils studied in the vertical direction. In spite of the presence of minerals that can contribute to the process of salinization/sodification, such contribution should be minimum when compared to the low quality of irrigation water. The reutilization of these soils with irrigated agriculture should be preceded of liming and of an efficient drainage system that prevents water table rise and promotes the leaching of sodium.

Index terms: sodic soils, salinity, soil chemicophysical properties, soil morphological features, semiarid.

\section{Introdução}

A prática da irrigação tem permitido o aumento da produtividade das culturas, por diminuir a irregulari-

(1) Aceito para publicação em 16 de abril de 2002. Trabalho financiado pelo CNPq/Projeto Nordeste II.

(2) Universidade Federal Rural de Pernambuco, Rua Dom Manuel de Medeiros, s/no, Dois Irmãos, CEP 52171-030 Recife, PE. E-mail: lbdeoliveira@yahoo.com.br, rosas@truenet.com.br, agroboy@uol.com.br

(3) Universidade Católica de Pernambuco, Rua do Príncipe, 502, Boa Vista, CEP 50050-900 Recife, PE. E-mail: mgvxf@uol.com.br dade espacial e temporal do suprimento de água, possibilitando a expansão das fronteiras agrícolas em muitas regiões do globo, inclusive no Nordeste brasileiro. Com esta finalidade, e, sobretudo, na tentativa de regularizar o abastecimento de água para a população nordestina, o Departamento Nacional de Obras Contra a Seca (DNOCS) construiu umas três centenas de açudes em sua área de jurisdição, muitos dos quais passaram a constituir perímetros irrigados (Paiva, 1976). A criação desses perímetros irrigados aumentou a produtividade das terras dessa região, transformando, assim, a realidade sócio-econômico-cultural da sua população. 
No entanto, em decorrência do manejo inadequado, muitas dessas áreas encontram-se praticamente abandonadas, em virtude de problemas de salinidade/sodicidade em seus solos. Como exemplos, têm-se as seguintes áreas, em porcentual, afetadas por sais: Custódia, PE, com 97\%; Ceraíma, BA, com 32\%; São Gonçalo, Sumé e Cachoeira II, PB, com, respectivamente, 52, 61 e 30\% (Macêdo, 1988).

A escolha de áreas para compor perímetros irrigados nem sempre foi suficientemente embasada em critérios técnico-econômicos. Este fato, associado à falta de habilidade de parte dos irrigantes no manejo da irrigação e às peculiaridades edafoclimáticas do Nordeste brasileiro, muito tem contribuído para o processo de degradação de solos da região, resultando em índices como os acima citados.

No perímetro irrigado de Custódia, as atividades foram praticamente interrompidas a partir dos anos 80, em decorrência da salinização/sodificação de seus solos e do rebaixamento do nível d'água do açude.

Na definição de práticas adequadas de manejo, conservação e recuperação de um determinado solo, é imprescindível o conhecimento da natureza do solo em questão, uma vez que cada tipo de solo responderá de forma mais ou menos diferenciada a uma mesma prática. Normalmente, a resposta expressa-se pelo aumento ou diminuição da produtividade das culturas. Como exemplo, pode-se citar a diminuição da produtividade das culturas com o aumento da salinidade dos solos (Richards, 1973).

Como a maior parte da área do perímetro irrigado de Custódia apresenta solos afetados por sais (Macêdo, 1988), faz-se necessário gerar informações que possam auxiliar na definição de práticas de manejo e recuperação destes solos e na transferência de agrotecnologia.

O objetivo deste trabalho foi avaliar as propriedades e o comportamento de solos aluviais do perímetro irrigado de Custódia, PE, cujo uso agrícola foi interrompido em virtude de problemas de salinidade/ sodicidade.

\section{Material e Métodos}

O sítio de amostragem localiza-se no perímetro irrigado do DNOCS, no Município de Custódia, PE. Foram descritos três perfis de solos ao longo de um caminhamento transversal ao canal de drenagem natural, na planície de inundação.

A descrição dos perfis e a coleta das amostras, deformadas e indeformadas, seguiram as recomendações de Lemos \& Santos (1996), e foram realizadas em março de 1998.

As análises físicas e químicas foram realizadas de acordo com Embrapa (1997), com três repetições para cada amostra (horizonte); os resultados foram representados pelas médias.

As análises físicas incluíram determinações da granulometria, pelo método do densímetro, empregandose hexametafosfato de sódio como dispersante químico; argila natural; densidade global pelo método do anel volumétrico $-250 \mathrm{~cm}^{3}$; densidade das partículas; capacidade de campo e ponto de murcha permanente (extrator de Richards) e condutividade hidráulica do solo saturado.

As análises químicas consistiram em determinações do $\mathrm{pH}$ (aferido em água e $\mathrm{KCl} 1 \mathrm{M}$ ), do complexo sortivo $\mathrm{Ca}^{2+}, \mathrm{Mg}^{2+}$ e $\mathrm{Al}^{3+}$ extraídos com solução de $\mathrm{KCl} 1 \mathrm{M}$, sendo $\mathrm{Ca}^{2+} \mathrm{e} \mathrm{Mg}^{2+}$ determinados por espectrofotometria de absorção atômica, e $\mathrm{Al}^{3+}$, por titulação; $\mathrm{Na}^{+} \mathrm{e} \mathrm{K}{ }^{+}$, extraídos com solução de $\mathrm{HCl} 0,05 \mathrm{M}$ e $\mathrm{H}_{2} \mathrm{SO}_{4} 0,0125 \mathrm{M}$ e determinados por espectrofotometria de chama; $\mathrm{H}^{+}+\mathrm{Al}^{3+}$ (extraídos com solução de acetato de cálcio $0,5 \mathrm{M} \mathrm{a} \mathrm{pH} \mathrm{7,0}$ e determinados por titulação com $\mathrm{NaOH} 0,0606 \mathrm{M}$ ); $\mathrm{P}$ disponível (extraído com solução de $\mathrm{HCl}$ 0,05 M e determinado por colorimetria); e, C orgânico (determinado por oxidação via úmida com dicromato de potássio). No extrato da pasta de saturação foram determinados $\mathrm{pH}$, condutividade elétrica, $\mathrm{Ca}^{2+}, \mathrm{Mg}^{2+}, \mathrm{K}^{+}$e $\mathrm{Na}^{+}, \mathrm{CO}_{3}{ }^{-}$e $\mathrm{HCO}_{3}{ }^{-}$.

A partir dos dados acima obtidos, foram calculados conforme Embrapa (1997): relação silte/argila, grau de floculação, porosidade total, água disponível, soma de bases (S), capacidade de troca de cátions (CTC), saturação por bases (V\%), porcentagem de saturação por alumínio (PSA), porcentagem de saturação por sódio (PST) e relação de adsorção de sódio (RAS).

As frações cascalho e areia foram analisadas em lupa binocular. Para identificação dos minerais dessas frações, além da análise óptica, realizaram-se testes químicos com $\mathrm{H}_{2} \mathrm{O}_{2} 30 \%$, e de atração magnética com ímã de bolso.

A preparação das lâminas orientadas das frações silte e argila, saturadas com K e Mg-glicerol, foi feita segundo Jackson (1975). As lâminas saturadas com potássio foram processadas à temperatura ambiente e após aquecimento a $550^{\circ} \mathrm{C}$, por duas horas. As saturadas com magnésio foram solvatadas com glicerol e processadas à temperatura ambiente. 


\section{Resultados e Discussão}

A partir das descrições morfológicas e dos dados analíticos, os solos foram classificados até o 4o nível, com fases, segundo os critérios estabelecidos no Sistema Brasileiro de Classificação de Solos (Embrapa, 1999). O perfil 1 foi classificado como Neossolo Flúvico Ta eutrófico solódico A fraco textura argilosa/média/arenosa; o perfil 2 como Neossolo
Flúvico Sódico salino A fraco textura média/arenosa fase caatinga de várzea relevo plano e o perfil 3 como Neossolo Flúvico Sódico típico A fraco textura média fase caatinga de várzea relevo plano (Tabela 1).

A feição morfológica mais típica destes solos é a estratificação, decorrente dos diferentes ciclos de sedimentação dos materiais que os constituem (Oliveira et al., 1992). A estratificação, observada no campo, pode ser facilmente constatada pela análise

Tabela 1. Características morfológicas de solos aluviais do perímetro irrigado de Custódia, PE.

\begin{tabular}{|c|c|c|c|c|c|c|}
\hline Horizonte & $\begin{array}{l}\text { Profun- } \\
\text { didade } \\
(\mathrm{cm})\end{array}$ & Cor (solo úmido) & Textura & Estrutura & $\begin{array}{c}\text { Consistência (solo seco, úmido e } \\
\text { molhado) }\end{array}$ & Transição \\
\hline \multicolumn{7}{|c|}{ Perfil 1 - Neossolo Flúvico Ta eutrófico solódico } \\
\hline Apn & $0-15$ & $\begin{array}{l}\text { Bruno muito escuro } \\
(10 Y R 2 / 2)\end{array}$ & $\begin{array}{l}\text { Franco- } \\
\text { argilosa }\end{array}$ & $\begin{array}{l}\text { Fraca média blocos } \\
\text { subangulares }\end{array}$ & $\begin{array}{l}\text { Extremamente dura, firme, plástica e } \\
\text { muito pegajosa }\end{array}$ & $\begin{array}{l}\text { Gradual e } \\
\text { plana }\end{array}$ \\
\hline $\mathrm{Cn}_{1}$ & $15-45$ & $\begin{array}{l}\text { Bruno muito escuro } \\
(10 Y R 2 / 2)\end{array}$ & $\begin{array}{l}\text { Franco- } \\
\text { argilosa }\end{array}$ & $\begin{array}{l}\text { Fraca média a grande blocos } \\
\text { subangulares }\end{array}$ & $\begin{array}{l}\text { Extremamente dura, muito firme, } \\
\text { plástica e muito pegajosa }\end{array}$ & $\begin{array}{l}\text { Gradual e } \\
\text { plana }\end{array}$ \\
\hline $\mathrm{Cn}_{2}$ & $45-98$ & $\begin{array}{l}\text { Bruno-acinzentado muito } \\
\text { escuro }(10 \text { YR } 3 / 2)\end{array}$ & $\begin{array}{l}\text { Franco- } \\
\text { argilosa }\end{array}$ & $\begin{array}{l}\text { Fraca pequena a média blocos } \\
\text { subangulares }\end{array}$ & $\begin{array}{l}\text { Muito dura, firme, plástica e muito } \\
\text { pegajosa }\end{array}$ & $\begin{array}{l}\text { Abrupta e } \\
\text { plana }\end{array}$ \\
\hline $2 \mathrm{Cn}_{3}$ & $98-130$ & Bruno-escuro (10YR 3/3) & $\begin{array}{l}\text { Franco- } \\
\text { arenosa }\end{array}$ & Maciça moderadamente coesa & $\begin{array}{l}\text { Muito dura, friável e firme, ligeira- } \\
\text { mente plástica e ligeiramente pegajosa }\end{array}$ & $\begin{array}{l}\text { Clara e } \\
\text { plana }\end{array}$ \\
\hline $3 \mathrm{Cn}_{4}$ & $130-160$ & $\begin{array}{l}\text { Bruno-acinzentado-escuro } \\
\text { (10YR 4/2) }\end{array}$ & $\begin{array}{l}\text { Franco- } \\
\text { arenosa }\end{array}$ & Maciça moderadamente coesa & $\begin{array}{l}\text { Muito dura, muito friável, ligeira- } \\
\text { mente plástica e ligeiramente pegajosa }\end{array}$ & $\begin{array}{l}\text { Abrupta e } \\
\text { plana }\end{array}$ \\
\hline $4 \mathrm{Cn}_{5}$ & $160-210$ & $\begin{array}{l}\text { Bruno-amarelado-escuro } \\
(10 Y R \text { 4/4) }\end{array}$ & Areia & Maciça pouco coesa & $\begin{array}{l}\text { Ligeiramente dura, não-plástica e não- } \\
\text { pegajosa }\end{array}$ & - \\
\hline \multicolumn{7}{|c|}{ Perfil 2 - Neossolo Flúvico Sódico salino } \\
\hline Apn & $0-15$ & $\begin{array}{l}\text { Bruno-acinzentado muito } \\
\text { escuro }(10 \text { YR } 3 / 2)\end{array}$ & Franca & $\begin{array}{l}\text { Fraca pequena a média blocos } \\
\text { subangulares }\end{array}$ & Muito dura, firme, plástica e pegajosa & $\begin{array}{l}\text { Gradual e } \\
\text { plana }\end{array}$ \\
\hline $\mathrm{Cnz}_{1}$ & $15-50$ & $\begin{array}{l}\text { Bruno-acinzentado-escuro } \\
(10 \mathrm{YR} 3 / 2)\end{array}$ & $\begin{array}{l}\text { Franco- } \\
\text { argilo- } \\
\text { arenosa }\end{array}$ & $\begin{array}{l}\text { Fraca média a grande } \\
\text { prismática, composta de fraca } \\
\text { média a grande blocos } \\
\text { subangulares e angulares }\end{array}$ & $\begin{array}{l}\text { Extremamente dura, muito firme, } \\
\text { plástica e muito pegajosa }\end{array}$ & $\begin{array}{l}\text { Gradual e } \\
\text { plana }\end{array}$ \\
\hline $\mathrm{Cnz}_{2}$ & $50-105$ & $\begin{array}{l}\text { Bruno-acinzentado muito } \\
\text { escuro }(10 \mathrm{YR} 3 / 2)\end{array}$ & Franca & $\begin{array}{l}\text { Fraca pequena a média blocos } \\
\text { subangulares e angulares }\end{array}$ & Muito dura, firme, plástica e pegajosa & $\begin{array}{l}\text { Abrupta e } \\
\text { plana }\end{array}$ \\
\hline $2 \mathrm{Cn}_{1}$ & $105-138$ & Bruno-escuro (10YR 4/3) & $\begin{array}{l}\text { Areia- } \\
\text { franca }\end{array}$ & Maciça moderadamente coesa & $\begin{array}{l}\text { Ligeiramente dura, friável, não- } \\
\text { plástica e não-pegajosa }\end{array}$ & $\begin{array}{l}\text { Clara e } \\
\text { plana }\end{array}$ \\
\hline $3 \mathrm{Cn}_{2}$ & $138-155$ & $\begin{array}{l}\text { Bruno-acinzentado-escuro } \\
(10 \text { YR 4/2) }\end{array}$ & $\begin{array}{l}\text { Franco- } \\
\text { arenosa }\end{array}$ & Maciça moderadamente coesa & $\begin{array}{l}\text { Dura, muito friável a friável, não- } \\
\text { plástica e ligeiramente pegajosa }\end{array}$ & $\begin{array}{l}\text { Abrupta e } \\
\text { plana }\end{array}$ \\
\hline $4 \mathrm{Cn}_{3}$ & $155-200$ & Bruno-amarelado (10YR 5/4) & Areia & Maciça pouco coesa & $\begin{array}{l}\text { Solta a ligeiramente dura, solta a } \\
\text { muito friável, não-plástica e não- } \\
\text { pegajosa }\end{array}$ & - \\
\hline \multicolumn{7}{|c|}{ Perfil 3 - Neossolo Flúvico Sódico típico } \\
\hline Ap & $0-15$ & $\begin{array}{l}\text { Bruno-acinzentado muito } \\
\text { escuro }(10 \mathrm{YR} 3 / 2)\end{array}$ & $\begin{array}{l}\text { Franco- } \\
\text { argilo- } \\
\text { arenosa }\end{array}$ & $\begin{array}{l}\text { Fraca pequena a grande blocos } \\
\text { subangulares }\end{array}$ & $\begin{array}{l}\text { Muito dura a extremamente dura, } \\
\text { firme, ligeiramente plástica e } \\
\text { ligeiramente pegajosa }\end{array}$ & $\begin{array}{l}\text { Abrupta e } \\
\text { plana }\end{array}$ \\
\hline $\mathrm{Cn}_{1}$ & $15-60$ & $\begin{array}{l}\text { Bruno-acinzentado-escuro } \\
\text { (10YR 4/2), mosqueado } \\
\text { comum pequeno e distinto } \\
\text { bruno-forte }(7,5 \text { YR } 5 / 8)\end{array}$ & $\begin{array}{l}\text { Franco- } \\
\text { argilo- } \\
\text { arenosa }\end{array}$ & $\begin{array}{l}\text { Fraca muito grande prismática, } \\
\text { composta de fraca muito } \\
\text { grande blocos angulares }\end{array}$ & $\begin{array}{l}\text { Extremamente dura, muito firme, } \\
\text { ligeiramente plástica e muito pegajosa }\end{array}$ & $\begin{array}{l}\text { Abrupta e } \\
\text { plana }\end{array}$ \\
\hline $2 \mathrm{Cn}_{2}$ & $60-72$ & $\begin{array}{l}\text { Bruno-amarelado (10YR 5/4), } \\
\text { mosqueado comum pequeno e } \\
\text { distinto bruno }(7,5 \mathrm{YR} 5 / 8)\end{array}$ & $\begin{array}{l}\text { Franco- } \\
\text { arenosa }\end{array}$ & Maciça moderadamente coesa & $\begin{array}{l}\text { Dura, friável, não-plástica e não- } \\
\text { pegajosa }\end{array}$ & $\begin{array}{l}\text { Abrupta e } \\
\text { plana }\end{array}$ \\
\hline $3 \mathrm{Cn}_{3}$ & $72-90$ & $\begin{array}{l}\text { Cinzento muito escuro } \\
(10 \mathrm{YR} 3 / 1)\end{array}$ & $\begin{array}{l}\text { Franco- } \\
\text { argilo- } \\
\text { arenosa }\end{array}$ & $\begin{array}{l}\text { Fraca muito grande blocos } \\
\text { angulares }\end{array}$ & $\begin{array}{l}\text { Extremamente dura, extremamente } \\
\text { firme, plástica e ligeiramente pegajosa }\end{array}$ & $\begin{array}{l}\text { Clara e } \\
\text { plana }\end{array}$ \\
\hline $4 \mathrm{Cn}_{4}$ & $90-120$ & $\begin{array}{l}\text { Bruno-acinzentado-escuro } \\
\text { (10YR 4/2) }\end{array}$ & $\begin{array}{l}\text { Franco- } \\
\text { argilo- } \\
\text { arenosa }\end{array}$ & Maciça coesa & $\begin{array}{l}\text { Extremamente dura, muito firme, } \\
\text { ligeiramente plástica e ligeiramente } \\
\text { pegajosa }\end{array}$ & $\begin{array}{l}\text { Clara e } \\
\text { plana }\end{array}$ \\
\hline $5 \mathrm{Cn}_{5}$ & $120-185$ & Bruno-acinzentado (10YR 5/2) & $\begin{array}{l}\text { Franco- } \\
\text { argilo- } \\
\text { arenosa }\end{array}$ & Maciça & $\begin{array}{l}\text { Extremamente dura, muito firme, } \\
\text { plástica e pegajosa }\end{array}$ & - \\
\hline
\end{tabular}


granulométrica (Tabela 2). As camadas mais argilosas foram observadas até a profundidade de $1 \mathrm{~m}$ nos perfis 1 e 2, e a profundidades maiores no perfil 3 $\left(5 \mathrm{Cn}_{5}\right)$. Argumenta-se que uma maior variabilidade entre as camadas de solos aluviais decorre de uma elevada variação do volume e da velocidade do agente transportador ao longo dos tempos. Assim, a maior estratificação constatada no presente trabalho indica que os ciclos de sedimentação foram mais heterogêneos para estes solos do que, por exemplo, os que originaram o solo estudado por Sauders et al. (1980); este solo, segundo os autores, apresentou camadas texturalmente homogêneas ao longo do perfil.

A evidente estratificação observada no campo está perfeitamente demonstrada na distribuição das partículas ao longo dos perfis (Tabela 3). Os teores mais elevados de areia grossa do que de areia fina a partir dos horizontes $4 \mathrm{Cn}_{5}, 4 \mathrm{Cn}_{3}$ e $4 \mathrm{Cn}_{4}$ nos perfis 1 , 2 e 3 respectivamente, em contraste com o que ocorreu nos horizontes antecedentes, reforçam a interpretação de descontinuidade litológica, como sugerido por Estados Unidos (1999). A distribuição das partículas nos solos dita as variações das suas pro- priedades, conforme discutido ao longo do texto.

A relação silte/argila é normalmente maior do que 0,7 , indicando, assim, o pouco desenvolvimento pedogenético dos solos em questão, que é reforçado pela abundância de minerais facilmente alteráveis nas frações cascalho, areia e silte.

A densidade global variou de 1,33 a 1,93 $\mathrm{t} \mathrm{m}^{-3}$, e os maiores valores foram encontrados nos horizontes superficiais, exceção feita ao perfil 3, que apresentou os valores mais elevados em subsuperfície. Os valores elevados de densidade global nos horizontes superficiais são, provavelmente, conseqüência do cultivo dos solos.

Os teores de água disponível apresentaram variações de 1 a $12 \%$ no perfil 1,1 a $9 \%$ no perfil 2 e 3 a $13 \%$ no perfil 3 (Tabela 3 ). Os teores mais elevados foram observados nas camadas mais argilosas dos três solos. As correlações entre os teores de argila e a umidade nos potenciais de $-0,034 \mathrm{e}-1,52 \mathrm{MPa}$ e a água disponível foram positivas e altamente significativas (Figura 1).

Os solos apresentaram valores muito baixos de condutividade hidráulica, especialmente nas camadas superficiais, e não foram registrados valores

Tabela 2. Composição granulométrica, argila natural, grau de floculação e relação silte/argila de solos aluviais do perímetro irrigado de Custódia, PE.

\begin{tabular}{|c|c|c|c|c|c|c|c|c|c|c|}
\hline $\begin{array}{l}\text { Hori- } \\
\text { zonte }\end{array}$ & $\begin{array}{l}\text { Profun- } \\
\text { didade } \\
(\mathrm{cm})\end{array}$ & Cascalho & TFSA & $\begin{array}{l}\text { Areia } \\
\text { grossa } \\
--\left(\mathrm{g} \mathrm{kg}^{-}\right.\end{array}$ & $\begin{array}{l}\text { Areia } \\
\text { fina } \\
\text { solo) }\end{array}$ & Silte & Argila & $\begin{array}{l}\text { Argila } \\
\text { natural }\end{array}$ & $\begin{array}{c}\text { Grau de } \\
\text { floculação }\end{array}$ & Silte/argila \\
\hline \multicolumn{11}{|c|}{ Perfil 1 - Neossolo Flúvico Ta eutrófico solódico } \\
\hline Apn & $0-15$ & 0 & 100 & 79 & 174 & 385 & 361 & 249 & 31 & 1,07 \\
\hline $\mathrm{Cn}_{1}$ & $15-45$ & 0 & 100 & 116 & 143 & 385 & 356 & 269 & 24 & 1,08 \\
\hline $\mathrm{Cn}_{2}$ & $45-98$ & 0 & 100 & 92 & 192 & 390 & 326 & 239 & 27 & 1,20 \\
\hline $2 \mathrm{Cn}_{3}$ & $98-130$ & 0 & 100 & 123 & 546 & 180 & 151 & 104 & 31 & 1,19 \\
\hline $3 \mathrm{Cn}_{4}$ & $130-160$ & 0 & 100 & 118 & 481 & 220 & 181 & 104 & 42 & 1,22 \\
\hline $4 \mathrm{Cn}_{5}$ & $160-210$ & 0 & 100 & 735 & 186 & 10 & 69 & 19 & 76 & 0,00 \\
\hline \multicolumn{11}{|c|}{ Perfil 2 - Neossolo Flúvico Sódico salino } \\
\hline Apn & $0-15$ & 0 & 100 & 118 & 322 & 330 & 231 & 99 & 57 & 1,43 \\
\hline $\mathrm{Cnz}_{1}$ & $15-50$ & 0 & 100 & 98 & 396 & 265 & 241 & 129 & 46 & 1,10 \\
\hline $\mathrm{Cnz}_{2}$ & $50-105$ & 0 & 100 & 88 & 376 & 310 & 226 & 149 & 34 & 1,37 \\
\hline $2 \mathrm{Cn}_{1}$ & $105-138$ & 0 & 100 & 379 & 451 & 80 & 91 & 49 & 46 & 0,88 \\
\hline $3 \mathrm{Cn}_{2}$ & $138-150$ & 0 & 100 & 207 & 533 & 140 & 121 & 79 & 35 & 1,16 \\
\hline $4 \mathrm{Cn}_{3}$ & $150-200+$ & 4 & 96 & 862 & 67 & 30 & 41 & 9 & 78 & 0,73 \\
\hline \multicolumn{11}{|c|}{ Perfil 3 - Neossolo Flúvico Sódico típico } \\
\hline Ap & $0-15$ & 1 & 99 & 181 & 408 & 230 & 181 & 99 & 45 & 1,27 \\
\hline $\mathrm{Cn}_{1}$ & $15-60$ & 0 & 100 & 157 & 482 & 175 & 186 & 99 & 47 & 0,94 \\
\hline $2 \mathrm{Cn}_{2}$ & $60-72$ & 0 & 100 & 334 & 435 & 140 & 91 & 39 & 57 & 1,54 \\
\hline $3 \mathrm{Cn}_{3}$ & $72-90$ & 0 & 100 & 147 & 371 & 276 & 206 & 129 & 37 & 1,34 \\
\hline $4 \mathrm{Cn}_{4}$ & $90-120$ & 1 & 99 & 324 & 255 & 270 & 151 & 99 & 34 & 1,79 \\
\hline $5 \mathrm{Cn}_{5}$ & $120-185+$ & 2 & 98 & 294 & 215 & 180 & 311 & 269 & 13 & 0,58 \\
\hline
\end{tabular}


superiores a 1,5 $\mathrm{cm} \mathrm{h}^{-1}$ até a profundidade de $1 \mathrm{~m}$. Valores elevados para esse parâmetro foram registrados em subsuperfície, nas camadas onde os teores de areia foram superiores a $830 \mathrm{~g} \mathrm{~kg}^{-1}$ de solo $\left(4 \mathrm{Cn}_{5}\right.$ do perfil 1 , $2 \mathrm{Cn}_{1}$ e $4 \mathrm{Cn}_{3}$ do perfil 2).

A reação dos solos variou de moderadamente ácida a fortemente alcalina (Embrapa, 1999), com valores de $\mathrm{pH}$ em água entre 6,4 e 9,6. Todos apresentam $\Delta \mathrm{pH}$ negativo, o que indica o predomínio de cargas negativas na superfície dos colóides. Os valores mais elevados de pH estão associados aos mais altos teores de bicarbonato e sódio (solúvel e trocável), sugerindo a combinação desses elementos na forma de bicarbonato de sódio (Tabelas 4 e 5).

A variação nos teores das bases trocáveis é ampla, mas, quase sempre acompanha o aumento ou diminuição dos teores de argila. Os teores de $\mathrm{Ca}^{2+}$ variaram de 1,2 a 13,3; os de $\mathrm{Mg}^{2+}$, de 0,2 a 5,4; os de $\mathrm{K}^{+}$, de 0,20 a 2,23, e os $\mathrm{de} \mathrm{Na}^{+}$, de 0,56 a 16,40 cmol $_{\mathrm{c}} \mathrm{kg}^{-1}$ de solo (Tabela 4).
Os valores da CTC variaram de 2,20 a $22,6 \mathrm{cmol}_{\mathrm{c}} \mathrm{kg}^{-1}$ de solo, e no geral são mais elevados do que o encontrado por Ribeiro et al. (1994) em solos aluviais da planície do rio Brígida em Pernambuco. A CTC, da mesma forma que as bases trocáveis, está estreitamente relacionada à fração argila. A correlação entre os teores de argila e a CTC dos solos foi significativa e positiva (Figura 1). Resultados semelhantes foram obtidos em solos do Estado de São Paulo (Kiehl, 1979). Tais resultados reafirmam que a fração argila é a principal sede das reações físico-químicas dos solos e sedimentos (Krauskopf, 1967; Sparks, 1995). Os valores da CTC da fração argila estão de acordo com a sua composição mineralógica, que é constituída por minerais cauliníticos, micas, esmectitas e interestratificados irregulares.

A porcentagem de saturação por sódio foi elevada nos perfis 2 e 3 , conferindo-lhes o caráter sódico. O mesmo não ocorreu no perfil 1, embora tenha apresentado caráter solódico.

Tabela 3. Densidade, porosidade, parâmetros hídricos e condutividade hidráulica saturada de solos aluviais do perímetro irrigado de Custódia, PE.

\begin{tabular}{|c|c|c|c|c|c|c|c|c|}
\hline \multirow{4}{*}{$\begin{array}{l}\text { Hori- } \\
\text { zonte }\end{array}$} & \multirow{4}{*}{$\begin{array}{l}\text { Profun- } \\
\text { didade } \\
(\mathrm{cm})\end{array}$} & \multirow{2}{*}{\multicolumn{2}{|c|}{ Densidade }} & \multirow{4}{*}{$\begin{array}{l}\text { Porosidade } \\
----(\%)---\end{array}$} & \multicolumn{3}{|c|}{ Parâmetros hídricos } & \multirow{4}{*}{$\begin{array}{c}\text { Condutividade } \\
\text { hidráulica do solo } \\
\text { saturado }\left(\mathrm{cm} \mathrm{h}^{-1}\right)\end{array}$} \\
\hline & & & & & \multicolumn{2}{|c|}{ Umidade } & \multirow{3}{*}{$\begin{array}{c}\text { Água } \\
\text { disponível }\end{array}$} & \\
\hline & & Global & Partículas & & $0,034 \mathrm{MPa}$ & $1,52 \mathrm{MPa}$ & & \\
\hline & & ------ & $\left.\mathrm{m}^{-3}\right)-----$ & & & ----- $(\%)$--- & & \\
\hline \multicolumn{9}{|c|}{ Perfil 1 - Neossolo Flúvico Ta eutrófico solódico } \\
\hline Apn & $0-15$ & 1,62 & 2,52 & 36 & 24 & 12 & 12 & 0,0 \\
\hline $\mathrm{Cn}_{1}$ & $15-45$ & 1,58 & 2,53 & 38 & 24 & 12 & 12 & 0,0 \\
\hline $\mathrm{Cn}_{2}$ & $45-98$ & 1,45 & 2,52 & 42 & 22 & 11 & 12 & 0,0 \\
\hline $2 \mathrm{Cn}_{3}$ & $98-130$ & 1,39 & 2,62 & 47 & 8 & 4 & 4 & 2,3 \\
\hline $3 \mathrm{Cn}_{4}$ & $130-160$ & 1,35 & 2,67 & 49 & 12 & 6 & 6 & 0,8 \\
\hline $4 \mathrm{Cn}_{5}$ & $160-210$ & 1,37 & 2,60 & 47 & 3 & 2 & 1 & 58,8 \\
\hline \multicolumn{9}{|c|}{ Perfil 2 - Neossolo Flúvico Sódico salino } \\
\hline Apn & $0-15$ & 1,65 & 2,46 & 33 & 15 & 7 & 8 & 0,0 \\
\hline $\mathrm{Cnz}_{1}$ & $15-50$ & 1,66 & 2,55 & 35 & 17 & 8 & 9 & 0,0 \\
\hline $\mathrm{Cnz}_{2}$ & $50-105$ & 1,33 & 2,63 & 49 & 16 & 7 & 9 & 0,0 \\
\hline $2 \mathrm{Cn}_{1}$ & $105-138$ & 1,36 & 2,64 & 48 & 5 & 3 & 2 & 17,0 \\
\hline $3 \mathrm{Cn}_{2}$ & $138-150$ & 1,35 & 2,65 & 49 & 8 & 4 & 4 & 1,4 \\
\hline $4 \mathrm{Cn}_{3}$ & $150-200$ & 1,54 & 2,67 & 42 & 2 & 1 & 1 & 115,0 \\
\hline \multicolumn{9}{|c|}{ Perfil 3 - Neossolo Flúvico Sódico típico } \\
\hline Ap & $0-15$ & 1,64 & 2,60 & 37 & 12 & 6 & 6 & 1,5 \\
\hline $\mathrm{Cn}_{1}$ & $15-60$ & 1,61 & 2,65 & 39 & 10 & 5 & 5 & 1,1 \\
\hline $2 \mathrm{Cn}_{2}$ & $60-72$ & 1,55 & 2,69 & 42 & 6 & 3 & 3 & 1,3 \\
\hline $3 \mathrm{Cn}_{3}$ & $72-90$ & 1,90 & 2,60 & 27 & 16 & 7 & 9 & 0,0 \\
\hline $4 \mathrm{Cn}_{4}$ & $90-120$ & 1,39 & 2,57 & 46 & 12 & 5 & 7 & 0,0 \\
\hline $5 \mathrm{Cn}_{5}$ & $120-185$ & 1,93 & 2,65 & 27 & 25 & 12 & 13 & 0,0 \\
\hline
\end{tabular}


A condutividade elétrica do extrato de saturação foi elevada apenas no perfil 2, onde atingiu $6,7 \mathrm{dS} / \mathrm{m}$ na camada $\mathrm{Cnz}_{2}$ (Tabela 5). Considerando que a área amostrada deixou de ser cultivada em função da
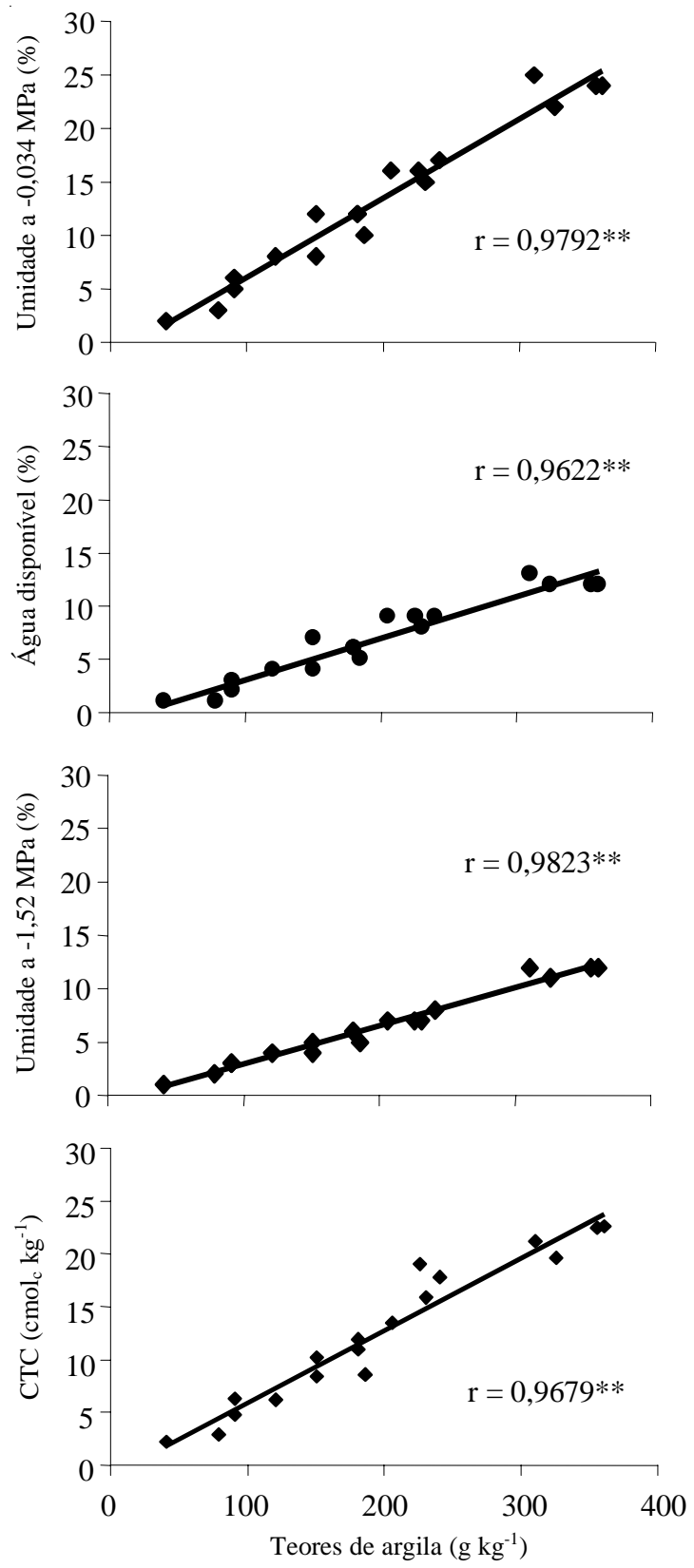

Figura 1. Correlações entre os teores de argila e umidade a -0,034 MPa e a -1,52 MPa, água disponível e CTC, em solos aluviais do Município de Custódia, PE. salinidade e sodicidade, atualmente a sodicidade é o problema mais limitante ao seu uso. Os sais solúveis devem ter sido removidos, em sua maior parte, pelas águas das chuvas que se seguiram ao abandono das áreas. Pereira et al. (1986) estudando o efeito da água de irrigação na elevação dos teores de sais e do potencial de lixiviação das chuvas em um solo de textura franco-arenosa no perímetro irrigado de Curu, PB, constataram que $300 \mathrm{~mm}$ de chuva foram suficientes para reconduzir o solo ao status salino inicial.

Entre os cátions solúveis, o $\mathrm{Na}^{+}$foi o que apresentou concentrações mais elevadas (Tabela 5). Isto se deve à sua maior solubilidade e ao fato de que cálcio e magnésio têm sua solubilidade diminuída à medida que o $\mathrm{pH}$ atinge valores mais elevados $(\mathrm{pH} \geq 8,5)$ que possibilitam a formação de $\mathrm{CO}_{3}{ }^{2-}$ (Sparks, 1995).

Silveira (2000), estudando o efeito da aplicação de gesso na água de irrigação sobre a dessalinização, dessodificação e condutividade hidráulica de solos do referido perímetro irrigado, em condições de laboratório, constatou uma tendência de diminuição da salinidade e sodicidade com o uso de água sintética, cuja composição era similar à do açude de Custódia. Esse resultado sugere que a lixiviação utilizando água do açude (classificada pela mesma como $\mathrm{C}_{3} \mathrm{~S}_{1}$ ) seria capaz de remover parte dos problemas causados pela salinidade/sodicidade. Tal afirmação deve ser analisada sob restrições, mas reforça a hipótese de que a salinidade e sodicidade elevaram-se nos solos do perímetro irrigado de Custódia, em conseqüência da elevação do lençol freático, associado a elevada evapotranspiração potencial da região. A ausência de sistema de drenagem e o manejo deficiente da irrigação devem ter sido as causas da elevação do lençol freático.

Os teores de $\mathrm{P}$ disponível foram elevados, variando de 37 a $71 \mathrm{mg} \mathrm{kg}^{-1}$ de solo. Tais teores podem ser resultado das adubações que foram realizadas nesses solos ao longo dos anos de cultivo. É, também, provável que o extrator utilizado tenha solubilizado parte do P não-disponível, como salientam Novais \& Smith (1999).

Os teores de carbono orgânico são baixos, porém compatíveis com a condição de semi-aridez da região. Seus valores mais elevados foram encontrados 
Tabela 4. Análises químicas de caracterização de solos aluviais do perímetro irrigado de Custódia, PE.

\begin{tabular}{|c|c|c|c|c|c|c|c|c|c|c|c|c|c|c|c|c|}
\hline \multirow{3}{*}{$\begin{array}{l}\text { Hori- } \\
\text { zonte }\end{array}$} & \multicolumn{2}{|c|}{$\mathrm{pH}$} & \multicolumn{8}{|c|}{ Complexo sortivo } & \multirow[t]{2}{*}{$\mathrm{V}$} & \multirow[t]{2}{*}{ PSA } & \multirow[t]{2}{*}{ PST } & \multirow[t]{2}{*}{$\mathrm{C}$} & \multirow[t]{2}{*}{$\mathrm{N}$} & \multirow[t]{2}{*}{$\mathrm{C} / \mathrm{N}$} \\
\hline & $\mathrm{H}_{2} \mathrm{O}$ & $\mathrm{KCl}$ & $\mathrm{Ca}^{2+}$ & $\mathrm{Mg}^{2+}$ & $\mathrm{K}^{+}$ & $\mathrm{Na}^{+}$ & $\mathrm{S}$ & $\mathrm{Al}^{3+}$ & $\mathrm{H}^{+}$ & $\mathrm{T}$ & & & & & & \\
\hline & & & \multicolumn{11}{|c|}{ - $\left(\mathrm{cmol}_{\mathrm{c}} \mathrm{kg}^{-1} \mathrm{de}\right.$ TFSA $)$} & \multicolumn{3}{|c|}{------ $\left(\mathrm{kg}^{-1}\right)$----- } \\
\hline \multicolumn{17}{|c|}{ Perfil 1 - Neossolo Flúvico Ta eutrófico solódico } \\
\hline Apn & 8,2 & 7,0 & 12,5 & 5,4 & 1,63 & 3,02 & 22,6 & 0,0 & 0,0 & 22,6 & 100 & 0 & 13 & 5,20 & 1,10 & 4,73 \\
\hline $\mathrm{Cn}_{1}$ & 8,1 & 6,7 & 13,1 & 5,2 & 1,15 & 3,01 & 22,5 & 0,0 & 0,0 & 22,5 & 100 & 0 & 13 & 3,80 & 0,90 & 4,22 \\
\hline $\mathrm{Cn}_{2}$ & 7,8 & 6,3 & 13,3 & 3,3 & 0,69 & 2,31 & 19,6 & 0,0 & 0,0 & 19,6 & 100 & 0 & 12 & 2,60 & 0,60 & 4,33 \\
\hline $2 \mathrm{Cn}_{3}$ & 8,1 & 6,2 & 5,8 & 1,4 & 0,41 & 0,80 & 8,4 & 0,0 & 0,0 & 8,4 & 100 & 0 & 10 & 0,90 & 0,20 & 4,50 \\
\hline $3 \mathrm{Cn}_{4}$ & 8,0 & 6,0 & 7,7 & 1,8 & 0,48 & 0,98 & 11,0 & 0,0 & 0,0 & 11,0 & 100 & 0 & 9 & 1,00 & 0,30 & 3,33 \\
\hline $4 \mathrm{Cn}_{5}$ & 8,2 & 6,2 & 1,8 & 0,3 & 0,20 & 0,62 & 2,9 & 0,0 & 0,0 & 2,9 & 100 & 0 & 21 & 0,40 & 0,10 & 4,00 \\
\hline \multicolumn{17}{|c|}{ Perfil $2-$ Neossolo Flúvico Sódico salino } \\
\hline Apn & 7,5 & 6,7 & 8,1 & 3,7 & 2,23 & 1,83 & 15,9 & 0,0 & 0,0 & 15,9 & 100 & 0 & 12 & 3,80 & 0,80 & 4,75 \\
\hline $\mathrm{Cnz}_{1}$ & 8,8 & 7,5 & 7,6 & 3,2 & 0,48 & 6,56 & 17,8 & 0,0 & 0,0 & 17,8 & 100 & 0 & 37 & 1,60 & 0,40 & 4,00 \\
\hline $\mathrm{Cnz}_{2}$ & 8,2 & 6,9 & 8,1 & 3,7 & 0,34 & 6,87 & 19,0 & 0,0 & 0,0 & 19,0 & 100 & 0 & 36 & 1,40 & 0,40 & 3,50 \\
\hline $2 \mathrm{Cn}_{1}$ & 7,6 & 6,4 & 3,2 & 1,4 & 0,28 & 1,40 & 6,3 & 0,0 & 0,0 & 6,3 & 100 & 0 & 22 & 0,50 & 0,20 & 2,50 \\
\hline $3 \mathrm{Cn}_{2}$ & 8,1 & 6,3 & 3,9 & 0,5 & 0,36 & 1,45 & 6,2 & 0,0 & 0,0 & 6,2 & 100 & 0 & 23 & 0,60 & 0,20 & 3,00 \\
\hline $4 \mathrm{Cn}_{3}$ & 8,2 & 6,4 & 1,2 & 0,2 & 0,20 & 0,56 & 2,2 & 0,0 & 0,0 & 2,2 & 100 & 0 & 26 & 0,20 & 0,10 & 2,00 \\
\hline \multicolumn{17}{|c|}{ Perfil 3 - Neossolo Flúvico Sódico típico } \\
\hline Ap & 6,4 & 5,7 & 5,6 & 3,0 & 1,34 & 0,59 & 10,5 & 0,0 & 1,4 & 11,9 & 88 & 0 & 5 & 5,30 & 1,10 & 4,82 \\
\hline $\mathrm{Cn}_{1}$ & 7,7 & 5,7 & 5,2 & 2,0 & 0,39 & 1,08 & 8,6 & 0,0 & 0,0 & 8,6 & 100 & 0 & 13 & 0,90 & 0,30 & 3,00 \\
\hline $2 \mathrm{Cn}_{2}$ & 8,4 & 6,0 & 2,8 & 0,8 & 0,26 & 0,95 & 4,8 & 0,0 & 0,0 & 4,8 & 100 & 0 & 20 & 0,40 & 0,20 & 2,00 \\
\hline $3 \mathrm{Cn}_{3}$ & 8,4 & 6,1 & 5,3 & 3,8 & 0,47 & 3,97 & 13,5 & 0,0 & 0,0 & 13,5 & 100 & 0 & 29 & 0,90 & 0,20 & 4,50 \\
\hline $4 \mathrm{Cn}_{4}$ & 9,3 & 6,2 & 3,6 & 2,2 & 0,42 & 4,05 & 10,2 & 0,0 & 0,0 & 10,2 & 100 & 0 & 40 & 0,60 & 0,20 & 3,00 \\
\hline $5 \mathrm{Cn}_{5}$ & 9,6 & 7,5 & 2,3 & 1,9 & 0,61 & 16,40 & 21,2 & 0,0 & 0,0 & 21,2 & 100 & 0 & 77 & 0,50 & 0,20 & 2,50 \\
\hline
\end{tabular}

Tabela 5. Fósforo disponível (P), pH, condutividade elétrica (CE), cátions solúveis, carbonato, bicarbonato e relação de adsorção de sódio (RAS) do extrato da pasta de saturação de solos aluviais do perímetro irrigado de Custódia, PE.

\begin{tabular}{|c|c|c|c|c|c|c|c|c|c|c|}
\hline Horizonte & $\begin{array}{c}\mathrm{P} \\
\left(\mathrm{mg} \mathrm{kg}^{-1}\right)\end{array}$ & $\mathrm{pH}$ & 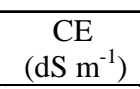 & $\mathrm{Ca}^{2+}$ & $\mathrm{Mg}^{2+}$ & $\mathrm{K}^{+}$ & $\begin{array}{r}\mathrm{Na}^{+} \\
101 \mathrm{~L}^{-1} \\
\end{array}$ & $\mathrm{CO}_{3}^{-}$ & $\mathrm{HCO}_{3}^{-}$ & RAS \\
\hline \multicolumn{11}{|c|}{ Perfil 1 - Neossolo Flúvico Ta eutrófico solódico } \\
\hline Apn & 66 & 9,3 & 2,0 & 6,2 & 3,4 & 0,3 & 9,5 & 0,7 & 3,0 & 4 \\
\hline $\mathrm{Cn}_{1}$ & 59 & 9,0 & 1,7 & 4,8 & 2,4 & 0,2 & 7,8 & 0,2 & 2,2 & 4 \\
\hline $\mathrm{Cn}_{2}$ & 56 & 7,9 & 1,6 & 5,1 & 1,7 & 0,1 & 6,7 & 0,0 & 0,5 & 4 \\
\hline $2 \mathrm{Cn}_{3}$ & 63 & 5,6 & 0,6 & 1,4 & 0,6 & 0,2 & 3,3 & 0,0 & 0,1 & 3 \\
\hline $3 \mathrm{Cn}_{4}$ & 63 & 7,3 & 0,6 & 1,6 & 0,5 & 0,1 & 3,3 & 0,0 & 0,3 & 3 \\
\hline $4 \mathrm{Cn}_{5}$ & 46 & 5,0 & 0,4 & 0,6 & 0,3 & 0,2 & 2,1 & 0,0 & 0,1 & 3 \\
\hline \multicolumn{11}{|c|}{ Perfil 2 - Neossolo Flúvico Sódico salino } \\
\hline Apn & 71 & 8,7 & 3,2 & 12,3 & 7,7 & 1,5 & 10,5 & 0,2 & 3,6 & 3 \\
\hline $\mathrm{Cnz}_{1}$ & 51 & 9,0 & 4,1 & 6,8 & 4,3 & 0,2 & 29,0 & 0,2 & 1,8 & 12 \\
\hline $\mathrm{Cnz}_{2}$ & 57 & 7,7 & 6,7 & 17,4 & 12,3 & 0,2 & 37,5 & 0,0 & 0,6 & 10 \\
\hline $2 \mathrm{Cn}_{1}$ & 53 & 6,5 & 2,9 & 9,8 & 6,2 & 0,2 & 10,4 & 0,0 & 0,1 & 4 \\
\hline $3 \mathrm{Cn}_{2}$ & 62 & 6,8 & 1,4 & 2,2 & 1,7 & 0,2 & 7,8 & 0,0 & 0,2 & 6 \\
\hline $4 \mathrm{Cn}_{3}$ & 41 & 5,8 & 0,4 & 0,5 & 0,4 & 0,2 & 2,7 & 0,0 & 0,2 & 4 \\
\hline \multicolumn{11}{|c|}{ Perfil 3 - Neossolo Flúvico Sódico típico } \\
\hline Ap & 37 & 8,5 & 1,4 & 6,6 & 5,5 & 0,8 & 1,8 & 0,1 & 2,9 & 1 \\
\hline $\mathrm{Cn}_{1}$ & 40 & 8,0 & 0,7 & 1,4 & 1,0 & 0,2 & 3,9 & 0,0 & 0,9 & 4 \\
\hline $2 \mathrm{Cn}_{2}$ & 42 & 7,6 & 0,4 & 0,4 & 0,5 & 0,2 & 2,9 & 0,0 & 0,9 & 4 \\
\hline $3 \mathrm{Cn}_{3}$ & 57 & 8,4 & 1,8 & 1,8 & 1,6 & 0,1 & 12,6 & 0,0 & 0,9 & 10 \\
\hline $4 \mathrm{Cn}_{4}$ & 45 & 9,2 & 1,9 & 1,1 & 1,0 & 0,2 & 15,3 & 0,3 & 3,2 & 15 \\
\hline $5 \mathrm{Cn}_{5}$ & 45 & 8,9 & 1,8 & 0,2 & 0,6 & 0,4 & 17,2 & 0,3 & 6,2 & 29 \\
\hline
\end{tabular}


nos horizontes superficiais, e diminuíram com a profundidade. A mesma tendência é demonstrada em relação ao $\mathrm{N}$ total. A baixa relação $\mathrm{C} / \mathrm{N}$ de $2,0-4,8$ sugere uma forte mineralização da matéria orgânica.

A composição mineralógica dos solos é similar, tanto entre como dentro dos perfis. A fração cascalho é constituída por minerais de quartzo e feldspatos, concreções ferruginosas e fragmentos de rochas, todos arredondados a bem arredondados, decorrência dos processos de transporte dos sedimentos.

Nas frações areia e silte, além dos minerais quartzo e feldspatos, foi identificada a presença de mica (Figura 2). Ferreyra \& Silva (1991), estudando a composição mineralógica da camada superficial $(0-20 \mathrm{~cm})$ de solos aluviais do perímetro irrigado de Morada Nova, CE, constaram que a fração areia era predominantemente composta por quartzo, e apresentava em menores proporções, micas (biotita e muscovita) e traços de outros minerais.

A fração argila dos solos é constituída por minerais de argila do grupo das caulinitas, micas, esmectitas e interestratificados irregulares (Figura 3).

A caulinita foi identificada pelos picos de $0,72 \mathrm{e}$ $0,36 \mathrm{~nm}$ nas amostras saturadas com $\mathrm{K}$, processadas à temperatura ambiente, que permaneceram quando da saturação com Mg-glicerol e colapsaram após aquecimento a $550^{\circ} \mathrm{C}$ das amostras saturadas com $\mathrm{K}$ (Jackson, 1975; Tan, 1996).

Os picos de 1,01, 0,50 e 0,33 nm nas amostras saturadas com K e processadas em temperatura ambiente, que permaneceram inalterados nos demais tratamentos, são diagnóstico na identificação de minerais de argila do grupo das micas (Jackson, 1975; Tan, 1996).

A presença de picos, na região, de 1,80 nm após tratamento com $\mathrm{Mg}$-glicerol, e seu colapso para $1,01 \mathrm{~nm}$ após aquecimento a $550^{\circ} \mathrm{C}$, é diagnóstico de minerais de argila do grupo das esmectitas (Jackson, 1975; Tan, 1996). A diminuição da intensidade do pico de 1,84 nm próximo à superfície do solo sugere uma diminuição da cristalinidade dos minerais esmectíticos gerada por uma menor estabilidade nesta condição. Já a assimetria basal entre os picos das micas e esmectitas atestam a presença de interestratificados irregulares, sugerindo uma transformação de mica em esmectita (Jackson, 1975).
Composição mineralógica semelhante foi encontrada por Ribeiro et al. (1994), em solos aluviais do Município de Parnamirim, PE. Uma mistura, na qual minerais 2:1, expansíveis (vermiculita e montmorilonita) e não-expansíveis (micas e ilita), eram predominantes em relação à caulinita e ao quartzo, foi constatada por Ferreyra \& Silva (1991) nos solos aluviais da planície do rio Barrabuiú, no Município de Morada Nova, CE.

A uniformidade de composição mineralógica dentro dos perfis indica que os sedimentos que originaram tais solos derivam de material lítico similar, e que a estratificação dos sedimentos é propiciada por variações no volume e velocidade das águas de transporte.

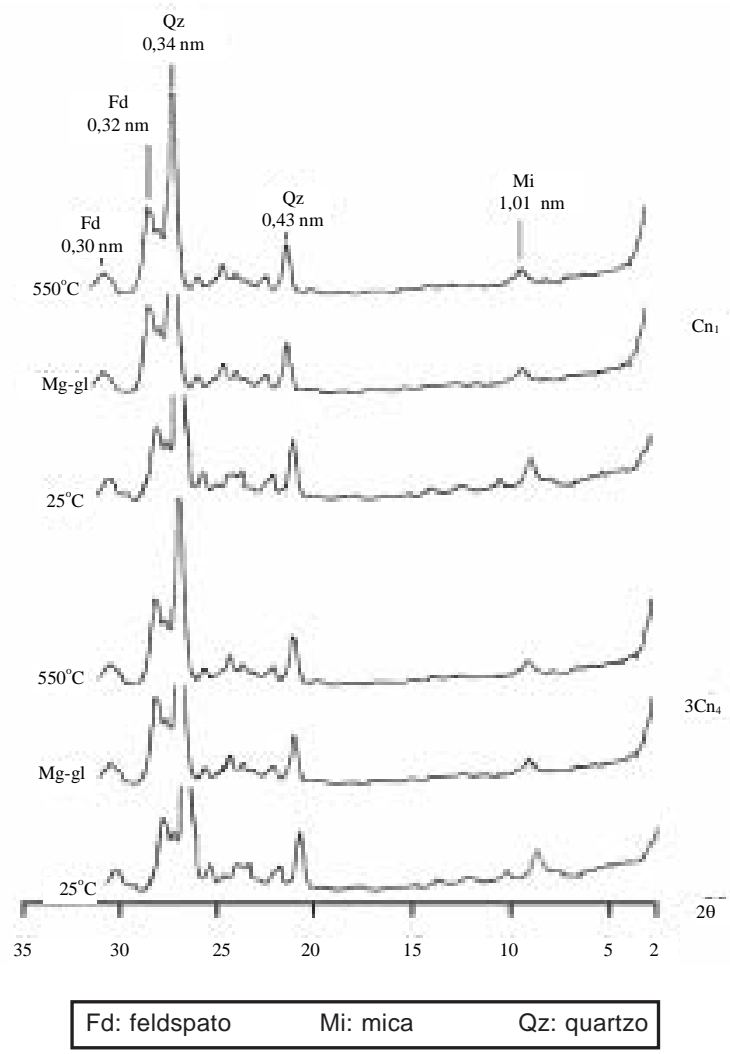

Figura 2. Difratogramas de raios-x da fração silte do perfil de Neossolo Flúvico Ta eutrófico solódico do perímetro irrigado de Custódia, PE. $25^{\circ} \mathrm{C}, 550^{\circ} \mathrm{C}$ e $\mathrm{Mg}$-gl indicam, respectivamente, saturação com $\mathrm{K}$ processada à temperatura ambiente, saturação com K processada após aquecimento e saturação com Mg-glicerol. 


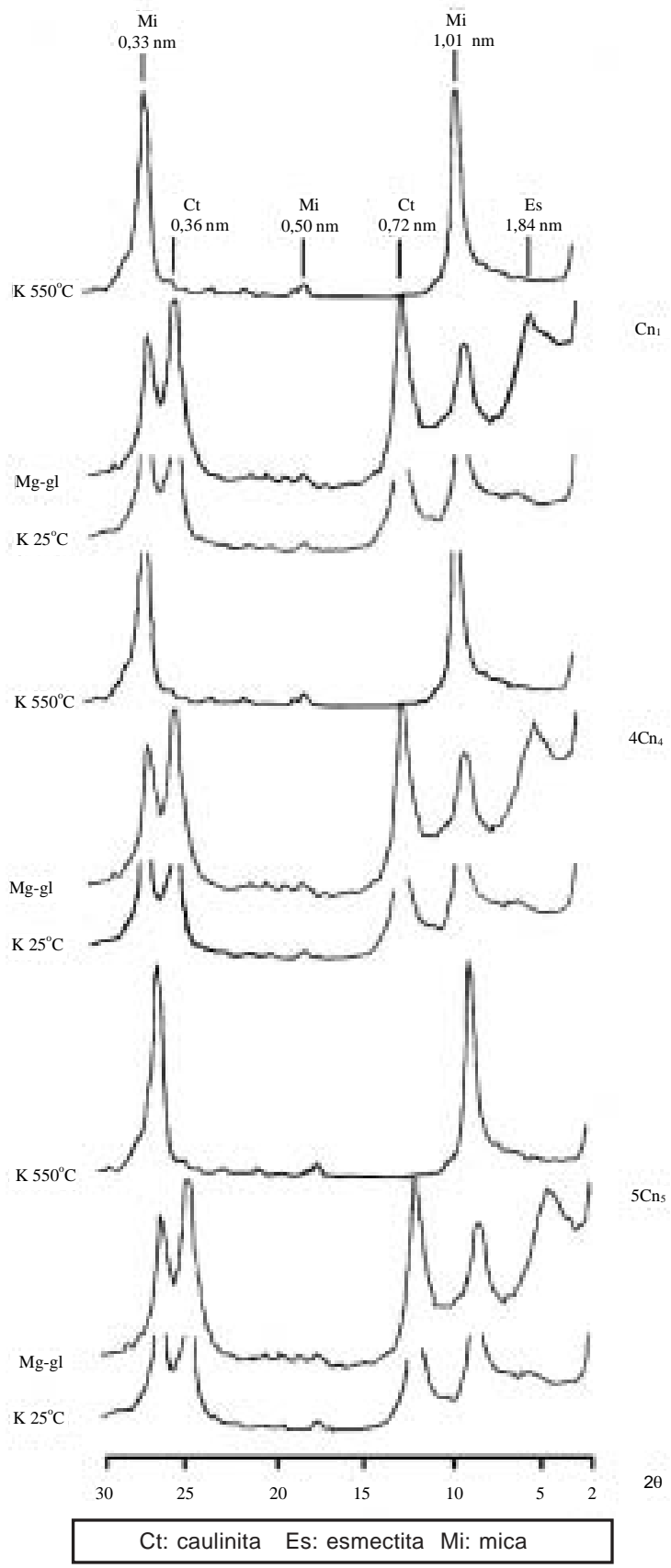

Figura 3. Difratogramas de raios-x da fração argila do perfil de Neossolo Flúvico Sódico típico do perímetro irrigado de Custódia, PE. $25^{\circ} \mathrm{C}, 550^{\circ} \mathrm{C}$ e Mg-gl indicam, respectivamente, saturação com $\mathrm{K}$ processada à temperatura ambiente, saturação com K processada após aquecimento e saturação com Mg-glicerol.

\section{Conclusões}

1. A estratificação, típica de solos de natureza aluvial, rege o comportamento dos atributos físicos e químicos dos solos estudados no sentido vertical.

2. A água de baixa qualidade é apontada como a principal fonte de sais solúveis, responsáveis pela degradação dos solos estudados.

3. A reutilização destes solos com agricultura irrigada deve ser precedida do uso de corretivos e da introdução de um eficiente sistema de drenagem que impeça a ascensão do lençol freático e promova a lixiviação do sódio.

\section{Referências}

EMBRAPA. Centro Nacional de Pesquisa de Solos (Rio de Janeiro, RJ). Manual de métodos de análises de solo. 2. ed. Rio de Janeiro: Embrapa-CNPS, 1997. 212 p.

EMBRAPA. Centro Nacional de Pesquisa de Solos (Rio de Janeiro, RJ). Sistema Brasileiro de Classificação de Solos. Brasília: Embrapa-SPI, 1999. 412 p.

ESTADOS UNIDOS. Department of Agriculture. Natural Resources Conservation Service. Soil Survey Staff. Soil taxonomy: a basic system of soil classification for making and interpretation of soil surveys. Washington, 1999. 870 p. (Agriculture Handbook, 436).

FERREYRA, F. F. H.; SILVA, F. R. Identificação mineralógica das frações areia e argila dos solos aluviais do perímetro K do projeto de irrigação de Morada Nova, Ceará. Ciência Agronômica, Fortaleza, v. 22, n. 1/2, p. 2937, jun./dez. 1991.

JACKSON, M. L. Soil chemical analysis: advanced course. 29. ed. Madison, 1975. 895 p.

KIEHL, E. J. Manual de edafologia. São Paulo: Ceres, 1979. $353 \mathrm{p}$.

KRAUSKOPF, K. B. Introduction to geochemistry. New York: McGraw-Hill, 1967. 721 p.

LEMOS, R. C.; SANTOS, R. D. Manual de descrição e coleta de solo no campo. 3. ed. Campinas: Sociedade Brasileira de Ciência do Solo, 1996. 84 p.

MACÊDO, L. de S. Salinidade em áreas irrigadas. João Pessoa: Empresa Estadual de Pesquisa Agropecuária, 1988. 11 p. (Comunicado Técnico, 38). 
NOVAIS, R. F.; SMITH, T. J. Fósforo em condições tropicais. Viçosa, MG: UFV, 1999. 399 p.

OLIVEIRA, J. B.; JACOMINE, P. K. T.; CAMARGO, M. N. Classes gerais de solos no Brasil: guia auxiliar para o seu reconhecimento. 2. ed. Jaboticabal: Fundação de Estudos e Pesquisas em Agronomia, Medicina Veterinária e Zootecnia, 1992. 201 p.

PAIVA, M. P. Considerações sobre a política de açudagem no Nordeste do Brasil. Boletim Cearense de Agronomia, Fortaleza, v. 17, p. 7-17, 1976.

PERREIA, O. J.; MATIAS FILHO, J.; ANDRADE, E. M. Variação do teor de sais no solo irrigado por aspersão e ação da chuva na sua lixiviação. Ciência Agronômica, Fortaleza, v. 17, n. 1, p. 61-65, jun. 1986.

RIBEIRO, M. R.; SOUZA, E. A. de; FERREIRA, M. G. V. X. Características de uma seqüência de solos na planície aluvial do rio Brígida em Parnamirim. Caderno Omega, Recife, n. 6, p. 137-149, 1994.

RICHARDS, L. A. Diagnostico y rehabilitación de suelos salinos y sódicos. México: Limura, 1973. 172 p.

SAUDERS, L. C. U.; MOTA, F. O. B.; CASTRO, P. T.; MATIAS FILHO, J. Caracterização morfológica, física e química de um solo aluvial na F. E. V. C. Ciência Agronômica, Fortaleza, v. 11, n. 2, p. 137-143, dez. 1980.

SILVEIRA, K. R. Influência da aplicação do gesso na água de irrigação sobre a salinidade, sodicidade e condutividade hidráulica de solo aluviais. Recife: UFRPE, 2000. 73 f. Dissertação (Mestrado em Ciência do Solo) - Universidade Federal Rural de Pernambuco, Recife.

SPARKS, D. L. Environmental soil chemistry. New York: Academic, 1995. 267 p.

TAN, K. H. Soil sampling, preparation and analysis. New York: M. Dekker, 1996. 408 p. 